\title{
Commentary: Single ventricle patients and shunts-ACute event is not pretty
}

\author{
Ronald K. Woods, MD, PhD, FACS, FAAP, and Viktor Hraska, MD, PhD
}

\footnotetext{
From the Division of Pediatric Cardiothoracic Surgery, Department of Surgery, Medical College of Wisconsin, and Herma Heart Institute, Children's Hospital of Wisconsin, Milwaukee, Wis.

Disclosures: Dr Woods is cofounder of OperVu, Inc, which has no relationship to the content of this work. Dr Hraska has nothing to disclose with regard to commercial support.

Received for publication April 8, 2019; accepted for publication April 8, 2019; available ahead of print May 17, 2019.

Address for reprints: Ronald K. Woods, MD, PhD, FACS, FAAP, Division of Pediatric Cardiothoracic Surgery, Department of Surgery, Medical College of Wisconsin, Children's Hospital of Wisconsin, 9000 W Wisconsin Ave, MS B 730, Milwaukee, WI 53226 (E-mail: rwoods@ chw.org).

J Thorac Cardiovasc Surg 2019;158:1154-5

$0022-5223 / \$ 36.00$

Copyright (c) 2019 by The American Association for Thoracic Surgery

https://doi.org/10.1016/j.jtcvs.2019.04.022
}

As a specialty, we need the benefit, but cannot escape the evil, of the systemic-to-pulmonary arterial shunt. If only for our emotional toll alone (the 3 AM "heart attack" page that the patient is getting a heparin bolus and undergoing cardiopulmonary resuscitation), let alone the effects on our patients, this is an important topic.

In a previous report of systemic-to-pulmonary arterial shunt in patients with biventricular circulation, Hobbes and colleagues ${ }^{1}$ introduced the notion of an acute event. In a similarly structured study for patients with singleventricle circulation published in this issue of the Journal, Santro and colleagues, ${ }^{2}$ writing for the same group, have clearly demonstrated that acute events were associated with worse survival. ${ }^{2}$ Although this is important, it is not a surprise, given the encompassing nature of their definition of an acute event. We find several other results, and the interpretations of Santro and colleagues, ${ }^{2}$ to be less than convincing. They did not evaluate (1) hemodynamics or any measures of cardiac output; (2) effect of dual-source pulmonary blood flow; (3) effect of antegrade cerebral perfusion through the shunt (for Norwood); or (4) effect of major postoperative bleeding - all of which could affect shunt performance. Santro and colleagues ${ }^{2}$ also did not evaluate the effect of shunt wrapping on shunt reintervention, and it is unclear how they determined that shunt stenosis did not lead to thrombosis and an acute event. Inspection after taking down a thrombosed shunt would seem to preclude conclusions about an in situ shunt. Even if we assume that the points of Santro and colleagues ${ }^{2}$ are valid, how should we use the information in practice? What is the upper level of benefit for hematocrit and survival, or the lower level of benefit and shunt thrombosis? What are those limits for $\mathrm{pH}$ and an acute event?

There may be a more useful and important message in this report regarding outcomes after a shunt reintervention.

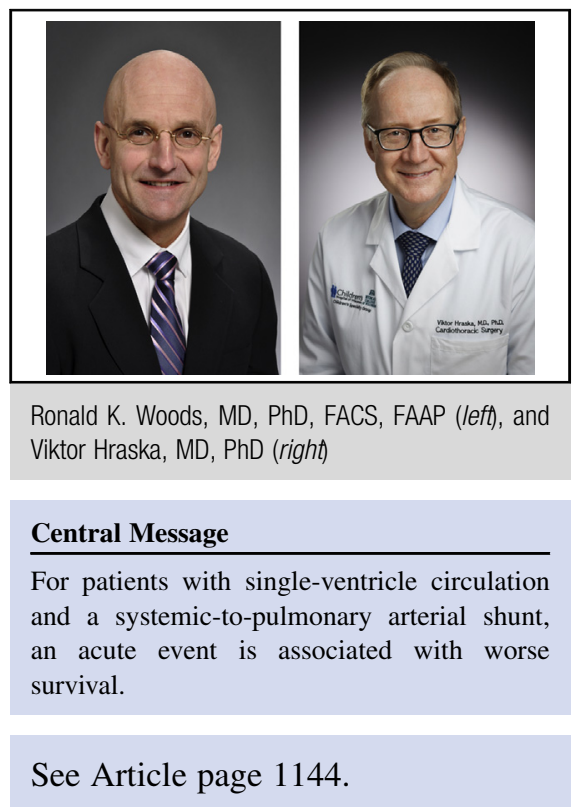

Santro and colleagues ${ }^{2}$ describe their technique of shunt "milking" (we will stay away from the rabbit hole issue of shunt reduction with wrap vs clip). Perhaps this is something that many surgeons do but simply do not report in the literature. We have used this technique in emergency circumstances but have always proceeded to immediate shunt revision, even if the milking restores good oxygenation, because of the concern for persistence of small amounts of material in the shunt and recurrent thrombosis. Santro and colleagues ${ }^{2}$ state that after a shunt-related acute event, immediate replacement was associated with better 30-day survival. Because the text is not clear, we can only infer that the comparison group was patients who underwent milking whose oxygen saturations were restored, and therefore did not have the shunt replaced.

Despite our respect for the insights of Santro and colleagues, ${ }^{2}$ we are hesitant to believe the "significance" of snapshot laboratory values and the "insignificance" of other variables consistently reported as risk factors (extracardiac anomaly, patient weight, use of extracorporeal membrane oxygenation, etc). Perhaps these are true and valid findings for the practice of Santro and colleagues. ${ }^{2}$ What is certainly true for all of us is that a beautiful shunt at 11 AM can become an unattractive disaster at $3 \mathrm{AM}$, and an acute event is far from pretty to us or our patients. 


\section{References}

1. Hobbes B, d'Udekem Y, Zannino D, Konstantinov IE, Brizard C, Brink J. Determinants of adverse outcomes after systemic-to-pulmonary shunts in biventricular circulation. Ann Thorac Surg. 2017;104:1365-70.

2. Santro T, d'Udekem Y, Zannino D, Hobbes B, Konstantinov IE, Brizard C, et al. Determinants of acute events leading to mortality after shunt procedure in univentricular palliation. J Thorac Cardiovasc Surg. 2019;158:1144-53.e6. 